\title{
Predictors of Burnout Syndrome Among Nigerian Physiotherapists
}

\author{
Ibikunle P.O., Umeadi O.C., Ummunah J. O. \\ Department of Medical Rehabilitation (Physiotherapy), Faculty of Health Sciences and Technology, College of \\ Health Sciences, Nnamdi Azikiwe University, Nnewi Campus, Anambra State \\ Correspondence \\ P.O. Ibikunle, Department of Medical Rehabilitation, Faculty of Health Sciences and Technology, College of \\ Health Sciences, Nnewi Campus•E-mail: pibikunle@yahoo.com
}

\section{SUMMARY}

Burnout syndrome is a worldwide phenomenon of considerable significance that has a detrimental impact on employees at all organizational levels and on organizations in their entirety, which translates into substantial human and economic cost. The purpose of this study is to find the association between some factors such as job satisfaction, victimization, proper remuneration, fear of workplace, and poor work environment with burnout syndrome among Nigerian physiotherapists. A total of 201 registered Nigerian physiotherapists (104 male and 97 female) participated in this study. The sample size was calculated using the Yaro Yamen formula and a disproportionate stratified random sampling technique was used to distribute the questionnaire to physiotherapists across the six geopolitical zones of Nigeria. The Maslach Burnout Inventory (MBI) and the Haris Stress Inventory (HSI) were the instruments used for the study. Data collected were analysed using descriptive statistics such as mean and standard deviation, and inferential statistics such as ANOVA, Spearman's correlation and the independent t-test. The results show that $38.8 \%$ (78) physiotherapists fear their workplace, $31.8 \%(64)$ were victimized by their superiors, $45.3 \%$ (91)were poorly remunerated, $39.3 \%$ (79) reported that their jobs were stressful, while $39.8 \%(80)$ were satisfied with their jobs. The study showed that the physiotherapists were experiencing high level of burnout.

Hospital management teams should create a conducive and comfortable working environment for their physiotherapists and make sure they are properly remunerated, while programmes should be organized to educate them on prevention, reduction and methods of coping with the syndrome.

KEYWORDS: burnout syndrome, physiotherapists

\section{INTRODUCTION}

A review of the literature shows that there is no clear-cut definition for burnout syndrome. It is a response to interpersonal stress on a job, which results in changes in attitude and behaviour towards people (Leiter and Maslach, 2001). It can be further defined as an individual's inability to cope with constant sources of stress (Kelly and Walvoored, 2006).
The sydrome has been extensively studied by Maslach and Jackson. The onset of burnout syndrome is characterized by a gradual loss of idealism, energy, enterprise and future aim, resulting in emotional overload and exhaustion (Price and Murphy, 1984). Authors have since categorized burnout symptoms into four categories, namely:

Affective manifestations - feelings of hopelessness, helplessness and powerlessness, a sense of failure, poor 
job-related esteem, impotence, impaired cognitive skills affecting memory and attention, negativism, pessimism, reduced empathy, distrust and an exceptionally critical attitude towards management, peers and supervisors;

Physical manifestations - regular bouts of flu, somatic complaints, higher level of cortisol and cholesterol and coronary heart disease;

Behavioural manifestations - substance abuse, absenteeism, staff turnover and impaired work performance); and

Motivational manifestations - a decline in and/or loss of enthusiasm, interest, idealism and zest, disillusionment, disappointment, resignation and submission, interpersonal conflicts and physical and mental withdrawal.

These symptoms apply to managerial and non-managerial employees, with low energy and lack of commitment as the more salient symptoms of leaders with significant burnout (Schaufeli and Buunk,2005). It is important to identify the factors that lead to burnout syndrome, recognize who is suffering from it and apply prevention techniques to stem the syndrome and stress at work places (Mirvis et al, 1999).

Factors that contribute to burnout syndrome include shortage of staff, compassion fatigue, work environment/place and job satisfaction. Gender, age, lower academic status, qualification, training, victimization and number of years in the field are indicators of who is suffering (Kelly and Walvoored, 2006). Staff shortage is not an unfamiliar problem in the healthcare sector. It causes occupational burnout syndrome due to the fact that health workers are expected to do more with few resources (Daugherty, 2002). Compassion fatigue is a job-related stress that is often overlooked (Blume 2002). It is a disorder and is not considered to be the same as burnout syndrome (Schwam,1998). Work environment has been shown to contribute to the different levels of burnout syndrome. It is expected that employees working in an unstable, chaotic work environment would experience higher levels of stress. Causes of stress in a poor organizational structure climate include inadequate guidance, lack of consultation, lack of communication and staff shortage (Al-ameri, 2003). Job satisfaction is another factor that has been shown as a serious predictor of burnout syndrome among health workers (Kalliath and Morris, 2002). Gender also plays a role in burnout syndrome.

Maslach's concept of burnout syndrome consists of three sequential levels or components that result from chronic stress (Maslach, 1982). These include emotional exhaustion (EE), depersonalization (DP), and decreased sense of personal accomplishment (PA). Emotional exhaustion is the first stage of the burnout syndrome. It is characterized by feelings of emotional exhaustion and lack of energy. This occurs when the demands of others increase. And when an individual continues to feel emotionally-overwhelmed, depersonalization (DP) can set in. This is the second stage of the burnout syndrome. It is characterized by feelings of detachment and dehumanization and involves inappropriate attempts to cope with EE. With time, DP develops into a decreased sense of personal accomplishment. This is a feeling of incompetence, inadequacy, personal failure and low professional esteem, which significantly affects the individual's ability to function (Maslach and Jackson,1984). Individuals with scores greater than or equal to 31 on the EE, 11 on the DP, and less than or equal to 35 on the PA subscales have high levels of burnout syndrome. Moderate levels include scores of 21-30 on EE, 6-10 on DP, and 41-36 on PA; while low levels include $<20, \leq 5$ and $\geq 42$ on the EE, DP and PA subscales respectively (Maslach and Leiter, 1997).

Physiotherapy is a healthcare profession concerned with movement and maximizing potential. It uses physical approaches to promote, maintain and restore physical, psychological and social well-being, taking into account variations in health status. It is science-based, and committed to extending, applying, evaluating and reviewing the evidence that underpins and informs its practice and delivery. The exercise of clinical judgment and informed interpretation is the core of the profession (Chartered Society of Physiotherapy, 2002).

\section{METHODOLOGY}

The research design is a survey conducted in the six geopolitical zones of Nigeria - south-south, southeast, southwest, north central, northeast, and northwest. According to the register of the Nigeria Society of Physiotherapy, as at December 2010, there were 1,300 registered physiotherapists in Nigeria. The sample size for this study as obtained from the Yaro Yamein formula for finite population was 306 .

\section{INSTRUMENT}

The Maslach Burnout Inventory (MBI) was used to assess burnout syndrome among Nigerian physiotherapists. It is a 22-question instrument that assesses the degree of burnout 
syndrome in terms of three subscales - emotional exhaustion (9 items), depersonalization (5 items), and decreased feeling of personal accomplishments (8 items). The frequency with which the respondents experienced each item is measured on a 7-point Likert-type scale anchored by never (0) and every day (6). The scores thus ranged from 0 to 54 on the EE subscale, 0 to 30 on the DP subscale, and 0 to 48 on the PA subscale. Because of limited psychometric evidence of the relationship between the subscales, the scores were considered separately and not combined into a single score (Pavlakis et al, 2010). A reliability coefficient of 0.90 was reported for EE, 0.79 for DP and 0.71 for PA (Price and Murphy, 1984). A second questionnaire, the Haris Stress Inventory was attached. This questionnaire was used to assess both individual and jobrelated stress. Five items were used to assess the job-related variables:

1. I fear my workplace.

2. I have been a scapegoat in a fight between two superiors (victimization).

3. My job is stressful.

4. I am not paid adequately (poor remuneration).

5. I am satisfied at work (job satisfaction).

\section{METHOD OF DATA COLLECTION}

The approval of the ethical committee of Nnamdi Azikiwe Teaching Hospital was obtained prior to the commencement of this study. Questionnaires were sent to the potential participants in stamped envelopes. Using the disproportionate stratified random sampling technique, 306 questionnaires were distributed to the six (6) geopolitical zones (51 per zone). The collation centres for the different zones were: University of Port-Harcourt Teaching Hospital (south-south); University of Nigeria Teaching Hospital (southeast); National Hospital, Abuja (north-central); Ahmadu Bello University Teaching Hospital (northwest), and University of Maiduguri Teaching Hospital (northeaast).

\section{METHOD OF DATA ANALYSIS}

Descriptive statistics such as mean, frequency, percentages and standard deviation were used in analysing the data. Inferential statistics like independent t-test, ANOVA and Spearman's correlation were used in testing hypothesis at 0.05 alpha level of significance.

\section{RESULTS}

\section{Socio-demographic Variables of Participating Physiotherapists}

The participants comprised $104(51.7 \%)$ males and (97) $48.3 \%$ females (table 1 ). The ages of the participants were: below 30 years $(28.4 \%), 30-39$ years $(34.8 \%)$, 40-49 years $28.4 \%$, while $8.4 \%$ were within the range of $50-59$ years. Also, $23.4 \%$ of the subjects had practiced for less than 5 years, $50.7 \%$ had practiced for between 5 and 10 years, while $25.9 \%$ had practiced for more than 10 years. In terms of marital status, $67.2 \%$ were married while $32.3 \%$ were single.

Table 1. Frequency distribution of Nigeria physiotherapists to different socio-demographic variables

\begin{tabular}{lcc}
\hline Variable & Frequency & Percentage (\%) \\
\hline Gender & 104 & 51.7 \\
Male & 97 & 48.3 \\
Female & & \\
Age & 57 & 28.4 \\
$<30$ years & 70 & 34.8 \\
30 - 39 years & 57 & 28.4 \\
40 - 49 years & 17 & 8.4 \\
50 - 59 years & 0 & 0.0 \\
$>59$ years & & \\
Years of Practice & 47 & 23.4 \\
$<5$ years & 102 & 50.7 \\
5 - 10 years & 52 & 25.9 \\
$>10$ years & & \\
Marital Status & 65 & 32.3 \\
Single & 135 & 67.2 \\
Married & & \\
\hline
\end{tabular}

\section{Factors Associated With Burnout Syndrome}

Table 2 shows that $38.8 \%$ of the participants feared their workplace, $51.7 \%$ did not fear their workplace, while $9.5 \%$ could not say whether they did or not. About $31.8 \%$ were victimized by their superiors, $53.7 \%$ were not victimized, while $14.4 \%$ gave no answer. In terms of remuneration, $45.3 \%$ believed that they were poorly remunerated, $31.3 \%$ believed that they were adequately remunerated, while $23.4 \%$ gave no answer. With regard to work satisfaction, $39.8 \%$ were satisfied at work, $38.8 \%$ were not, while $21.4 \%$ gave no answer. About $39.3 \%$ believed that their job 
was stressful, $43.3 \%$ did not perceive their job as being stressful, while $17.4 \%$ gave no answer.

Table 2. Factors associated with burnout syndrome

\begin{tabular}{lrc}
\hline Variable & Frequency & Percentage $(\%)$ \\
\hline Fear of Workplace & 78 & 38.8 \\
Yes & 104 & 51.7 \\
No & 19 & 9.5 \\
Cannot say & & \\
Victimization by Superiors & 64 & 31.8 \\
Yes & 108 & 53.7 \\
No & 29 & 14.4 \\
Cannot say & & \\
Poor Remuneration & 91 & 45.3 \\
Yes & 63 & 31.3 \\
No & 47 & 23.4 \\
Cannot say & & \\
Stressful Job & 79 & 39.3 \\
Yes & 87 & 43.3 \\
No & 35 & 17.4 \\
Cannot say & & \\
Job Satisfaction & 80 & 39.8 \\
Yes & 78 & 38.8 \\
No & 43 & 21.4 \\
Cannot say & & \\
\hline
\end{tabular}

\section{DISCUSSION}

The mean scores of the first stage of the burnout syndrome, i.e. EE, among Nigerian physiotherapists who feared their workplace and those who gave no answer were higher when compared with those that did not fear their workplace. There was no significant difference in the mean DP scores of those who feared their workplace, those who did not fear their workplace, and those who gave no answer. The results also show that the physiotherapists who feared their workplace and those who gave no answer have lower mean scores in the third stage of the burnout syndrome, i.e. PA, when compared with those who did not fear their workplace. This indicates that they were experiencing burnout. There was a very weak correlation between fear of workplace and EE and PA (negative and positive respectively), but there was no relationship between fear of workplace and DP.

The emotional exhaustion subscale affects mainly the organizational and social climate of the workplace (Maslach and Jackson, 1984). Nigerian physiotherapists probably showed high levels of EE due to their inability to adapt to the climate of their workplace. Nigerian physiotherapists experience high burnout in their workplace. This is corroborated by Segall and Burnett (1980) who stated that "employees working in an unstable chaotic work environment would deal with higher levels of stress and, hence, burnout syndrome."

The mean scores of EE were high for physiotherapists who were victimized by their superiors when compared with those who were not. The study also showed that the physiotherapists who were victimized had slightly higher mean scores for EE than those who were not victimized. There was however no significant difference in the mean scores of DP, but there were slight differences, as those who were victimized showed a higher level of depersonalization than those who were not. These findings are in agreement with similar studies which reported higher scores of EE in participants who lacked support from their superiors (Akroyd et al, 2002). The high level of EE exhibited by those who were victimized may have been as a result of poor cooperation and relationship with superiors and this could be a source of stress, which is the chief predictor of burnout syndrome.

The mean scores of the first and second stages of the burnout syndrome were significantly higher in physiotherapists who perceived their jobs as stressful and those who gave no answer, than in those who did not perceive their jobs as stressful. There were also lower levels of the third stage of burnout in physiotherapists who believed that their jobs were stressful compared to those who believed that their jobs were not stressful and had moderate burnout syndrome, according to the Maslach criteria for burnout syndrome. This also shows that victimization is a predictor of burnout syndrome. Although there is a very weak relationship between this job-related variable and the three stages of burnout; it is in agreement with a previous study on burnout syndrome in Cypriot physiotherapists, as they reported very high EE and DP subscales and very low PA subscales in participants who believed that their jobs were stressful (Pavlakis et al, 2010).

The onset of burnout syndrome, especially the first stage (EE), is when the physiotherapists perceive their jobs as stressful (Maslach,1982). The stress they go through in their jobs may be as a result of the challenges they face in dealing with their patients This is supported by the findings that an accumulation of a variety of stressors, including individual, interpersonal and organizational stress, drives the burnout process (Maslach et al, 1996). 
Predictors of Burnout Syndrome Among Nigerian Physiotherapists

Table 3. Fear of work place and stages of burnout syndrome

\begin{tabular}{|c|c|c|c|c|c|c|c|c|c|c|}
\hline Burnout Syndrome & Q1 & $\mathrm{N}$ & Mean $\pm S D$ & $\mathrm{~F}$ & $\mathrm{Df}$ & $\mathrm{P}$ & Remark & $\mathrm{R}$ & $\mathrm{P}$ & Remark \\
\hline \multirow[t]{3}{*}{$\mathrm{EE}$} & Yes & 78 & $41.19 \pm 7.83$ & 25.31 & 199 & 0.000 & S & -0.29 & 0.00 & $S$ \\
\hline & No & 104 & $28.82 \pm 13.39$ & & & & & & & \\
\hline & Cannot Say & 19 & $37.37 \pm 11.83$ & & & & & & & \\
\hline \multirow[t]{3}{*}{ DP } & Yes & 78 & $15.01 \pm 7.03$ & 3.02 & 199 & 0.051 & N.S & -0.09 & 0.18 & N.S \\
\hline & No & 104 & $13.50 \pm 7.42$ & & & & & & & \\
\hline & Cannot Say & 19 & $14.89 \pm 6.31$ & & & & & & & \\
\hline \multirow[t]{3}{*}{ PA } & Yes & 78 & $20.63 \pm 9.53$ & 10.47 & 199 & 0.00 & S & 0.02 & 0.61 & $S$ \\
\hline & No & 104 & $28.15 \pm 12.54$ & & & & & & & \\
\hline & Cannot Say & 19 & $22.63 \pm 9.19$ & & & & & & & \\
\hline
\end{tabular}

Key: $\mathrm{SD}=$ standard deviation; $\mathrm{Df}=$ degree of freedom; $\mathrm{P}=\mathrm{P}$-value; $\mathrm{S}=$ significant; $\mathrm{N} . \mathrm{S} .=$ not significant; $\mathrm{N}=$ number; $\mathrm{Q} 1=$ fear of work place; Test statistics = ANOVA

Table 4. Stages of burnout syndrome and victimization

\begin{tabular}{|c|c|c|c|c|c|c|c|c|c|c|}
\hline Burnout Syndrome & Q2 & $\mathrm{N}$ & Mean $\pm \mathrm{SD}$ & $\mathrm{F}$ & $\mathrm{Df}$ & $P$ & Remark & $\mathrm{R}$ & $P$ & Remark \\
\hline \multirow[t]{3}{*}{$\mathrm{EE}$} & Yes & 64 & $38.61 \pm 10.64$ & 5.750 & 199 & 0.004 & S & 0.14 & 0.05 & S \\
\hline & No & 108 & $31.78 \pm 13.83$ & & & & & & & \\
\hline & Cannot Say & 29 & $35.43 \pm 13.12$ & & & & & & & \\
\hline \multirow[t]{3}{*}{ DP } & Yes & 64 & $15.33 \pm 7.19$ & 2.862 & 199 & 0.060 & N.S & 0.10 & 0.14 & N.S \\
\hline & No & 108 & $12.64 \pm 7.42$ & & & & & & & \\
\hline & Cannot Say & 29 & $14.07 \pm 6.61$ & & & & & & & \\
\hline \multirow[t]{3}{*}{ PA } & Yes & 64 & $20.97 \pm 9.35$ & 9.000 & 199 & 0.000 & $S$ & 0.09 & 0.18 & N.S \\
\hline & No & 108 & $27.83 \pm 12.33$ & & & & & & & \\
\hline & Cannot Say & 29 & $21.34 \pm 10.83$ & & & & & & & \\
\hline
\end{tabular}

Key: $\mathrm{SD}=$ standard deviation; $\mathrm{Df}=$ degree of freedom; $\mathrm{P}=\mathrm{P}$-value; $\mathrm{S}=$ significant; $\mathrm{N} . \mathrm{S}$. $=$ not significant; $\mathrm{N}=$ number; $\mathrm{Q} 2=$ victimization by superiors; Test statistics $=$ ANOVA

Table 5. Stages of burnout syndrome and stressful job

\begin{tabular}{|c|c|c|c|c|c|c|c|c|c|c|}
\hline Burnout Syndrome & Q3 & $\mathrm{N}$ & Mean \pm SD & $\mathrm{F}$ & $\mathrm{Df}$ & $P$ & Remark & $\mathrm{R}$ & $\mathrm{P}$ & Remark \\
\hline \multirow[t]{3}{*}{ EE } & Yes & 79 & $41.92 \pm 8.53$ & 37.88 & 199 & 0.000 & $S$ & -0.33 & 0.00 & $S$ \\
\hline & No & 87 & $26.87 \pm 13.42$ & & & & & & & \\
\hline & Cannot Say & 35 & $36.29 \pm 10.49$ & & & & & & & \\
\hline \multirow[t]{3}{*}{ DP } & Yes & 79 & $15.49 \pm 6.53$ & 6.39 & 199 & 0.002 & $\mathrm{~S}$ & -0.15 & 0.03 & $S$ \\
\hline & No & 87 & $11.69 \pm 7.13$ & & & & & & & \\
\hline & Cannot Say & 35 & $14.66 \pm 7.99$ & & & & & & & \\
\hline \multirow[t]{3}{*}{ PA } & Yes & 79 & $18.42 \pm 8.89$ & 29.21 & 199 & 0.000 & $S$ & 0.40 & 0.00 & $S$ \\
\hline & No & 87 & $30.67 \pm 11.63$ & & & & & & & \\
\hline & Cannot Say & 35 & $24.11 \pm 9.85$ & & & & & & & \\
\hline
\end{tabular}

Key: $\mathrm{SD}=$ standard deviation; $\mathrm{Df}=$ degree of freedom; $\mathrm{P}=\mathrm{P}$-value; $\mathrm{S}=$ significant; $\mathrm{N} . \mathrm{S} .=$ not significant; $\mathrm{N}=$ number; $\mathrm{Q} 3=$ stressful job; Test statistics $=$ ANOVA 
Ibikunle, Umeadi, Ummunah,

Table 6. Stage of burnout syndrome and poor remuneration

\begin{tabular}{|c|c|c|c|c|c|c|c|c|c|c|}
\hline Burnout Syndrome & Q4 & $\mathrm{N}$ & Mean \pm SD & $\mathrm{F}$ & Df & $\mathrm{P}$ & Remark & $\mathrm{R}$ & $\mathrm{P}$ & Remark \\
\hline \multirow[t]{3}{*}{$\mathrm{EE}$} & Yes & 91 & $3779 \pm 10.92$ & 6.468 & 199 & 0.002 & S & -0.15 & 0.03 & S \\
\hline & No & 63 & $30.39 \pm 13.58$ & & & & & & & \\
\hline & Cannot Say & 47 & $33.32 \pm 13.58$ & & & & & & & \\
\hline \multirow[t]{3}{*}{ DP } & Yes & 91 & $15.18 \pm 6.68$ & 3.627 & 199 & 0.028 & $\mathrm{~S}$ & -0.17 & 0.01 & $\mathrm{~S}$ \\
\hline & No & 63 & $12.22 \pm 7.41$ & & & & & & & \\
\hline & Cannot Say & 47 & $12.83 \pm 7.41$ & & & & & & & \\
\hline \multirow[t]{3}{*}{ PA } & Yes & 91 & $23.03 \pm 11.05$ & 1.859 & 199 & 0.159 & $\mathrm{~S}$ & 0.98 & 0.16 & N.S \\
\hline & No & 63 & $26.58 \pm 11.78$ & & & & & & & \\
\hline & Cannot Say & 47 & $25.45 \pm 12.55$ & & & & & & & \\
\hline
\end{tabular}

Key: $\mathrm{SD}=$ standard deviation; $\mathrm{Df}=$ degree of freedom; $\mathrm{P}=\mathrm{P}$-value; $\mathrm{S}=$ significant; $\mathrm{N} . \mathrm{S} .=$ not significant; $\mathrm{N}=$ number; $\mathrm{Q} 4=$ poor remuneration; Test statistics $=$ ANOVA

Table 7. Stages of burnout syndrome and job satisfaction

\begin{tabular}{|c|c|c|c|c|c|c|c|c|c|c|}
\hline Burnout Syndrome & Q5 & $\mathrm{N}$ & Mean \pm SD & $\mathrm{F}$ & $\mathrm{Df}$ & $\mathrm{P}$ & Remark & $\mathrm{R}$ & $\mathrm{P}$ & Remark \\
\hline \multirow[t]{3}{*}{ EE } & Yes & 80 & $29.38 \pm 14.11$ & 17.699 & 199 & 0.000 & S & 0.16 & 0.02 & S \\
\hline & No & 78 & $40.65 \pm 9.56$ & & & & & & & \\
\hline & Cannot Say & 43 & $32.53 \pm 12.36$ & & & & & & & \\
\hline \multirow[t]{3}{*}{ DP } & Yes & 80 & $12.19 \pm 7.59$ & & 199 & 0.054 & N.S & 0.15 & 0.02 & S \\
\hline & No & 78 & $14.77 \pm 6.57$ & & & & & & & \\
\hline & Cannot Say & 43 & $14.58 \pm 7.44$ & & & & & & & \\
\hline \multirow[t]{3}{*}{ PA } & Yes & 80 & $29.54 \pm 12.26$ & & 199 & 0.000 & S & -0.14 & -0.24 & S \\
\hline & No & 78 & $19.98 \pm 59.52$ & & & & & & & \\
\hline & Cannot Say & 43 & $24.30 \pm 10.77$ & & & & & & & \\
\hline
\end{tabular}

The mean score of the first stage of the burnout syndrome in physiotherapists who were underpaid is significantly higher than those who were not underpaid and those who gave no response. There were also higher levels of depersonalization in participants who were poorly remunerated than in those who were not and those who could not say. Although not statistically significant, there exist slight differences in their personal accomplishment, as those who reported that they were well paid had higher levels of PA than others. The result also indicates that there is a very strong positive relationship between poor remuneration and $\mathrm{PA}$, while there is a very weak negative relationship between poor remuneration and the first and second stages of the syndrome. This is in line with the work done on burnout syndrome among Cypriot physiotherapists which reported high levels for the 3 subscales (Pavlakis et al, 2010).

The high levels of the first and second stages in participants who felt they were underpaid may have been as a result of the feeling that the poor salaries were not worth the stress they go through in their workplaces. Moreover, because they cannot leave their jobs and easily get another, they feel emotionally-exhausted and, subsequently, they experience burnout.

Job satisfaction is another predictor of burnout syndrome among health workers (Kelly and Walvoored, 2006). Evidence from other professions show that job satisfaction, in addition to being a positive motivator, may inhibit the effects of stress, a major cause of burnout syndrome (Akroyd et al, 2002).

In this study, physiotherapists who believed that they were satisfied at work showed lower levels of the first stage(EE) and second stage (DP) of the burnout syndrome when compared to those that were not satisfied and those that gave no response, and who reported high EE and PA. In a study conducted in 2002 on predictors of burnout syndrome among US nurses, it was concluded that higher levels of job satisfaction could reduce the levels of burnout 
Predictors of Burnout Syndrome Among Nigerian Physiotherapists

syndrome in employees (Kalliath and Morris, 2002), but the results demonstrated that emotional exhaustion strongly correlated with both job satisfaction and depersonalization.

\section{CONCLUSION}

It can be concluded that all the predictors affected the level of burnout syndrome in Nigerian physiotherapists. Although all the physiotherapists in the study were experiencing burnout, those that answered the questions in the affirmative experienced higher levels of burnout than those who answered no and those who were neutral. The hospital management teams should create a conducive and comfortable working environment for physiotherapists and properly remunerate them. Heads of physiotherapy departments should ensure that they cooperate with the physiotherapists working under them, and organize programmes on prevention, reduction and ways of coping with the syndrome.

\section{References}

Al-Aameri, A.S. 2003. Source of job stress for nurses in public hospitals. Saudi Medic Journal 24: 1183 - 1187.

Akroyd, D., A. Caison and R. Adams. 2002. Pattern of burnout among U.S Radiographers. Radiologic Technology73: 215223.

Blume, G.L. 2002. When caring hurts: The silent burnout of sonographers. Journal of Diagnostic Medical Sonography 18(6): 418 - 421.

Chartered Society of Physiotherapy. 2002. Curriculum Framework. Rules of Professional conduct.

Daugherty, J.M. 2002. Burnout: How sonographers and vascular technologist react to chronic stress. Journal of Diagnostic Medical Sonography 18(6): 305 -312.

Kalliath T and R Morris. 2002. Job satisfaction among nurses: A predictor of burnout level. Journal of Nursing Administration 32(12): 648-654.
Kelly, H. and B.S. Walvoored. 2006. Understanding sonographer burnout. Journal of Diagnostic Medical Sonography 22:200 205.

Leiter, P.M. and C. Maslach. 2001. Burnout and quality in a speed -up world. The Journal for Quality and Participation 24(2): 48-51.

Maslach, C. 1982. Burnout: A social-psychological analysis. In. J. W Jones (Ed). The Burnout Syndrome: Current Research, Theory and Interventions. Park Ridge, IL: London House Press.

Maslach, C. and S.E. Jackson. 1984. Burnout in organizational settings. Applied Social Psychology Annual 5: 133-153.

Maslach, C and M.P. Leiter. 1997. The Truth About Burnout San Francisco: Jossey-Bass.

Maslach, C., S.E. Jackson and M.P. Leiter. 1996. Maslach Burnout Inventory Manual $\left(3^{\text {rd }}\right.$ edition). Consulting Psychological Press.

Mirvis, D.M., M.J. Graney and D.P.A. Kilpatrick. 1999. Trends in burnout and related measures of organizational stress among leaders of department if veterans affairs medical centers. Journal of Healthcare Management 44(5): 353-366. .

Pavlakis,A., V. Raflopoulus and M. Theodorou. 2010. Burnout syndrome in Cypriot physiotherapists .BMC Health Services Research 10;63-78.

Price, D. and P. Murphy. 1984. Staff burnout in the perspective of grief theory. Death education 47-58.

Schaufeli, W.B. and B.P. Buunk. 2005. Burnout: An overview of 25 years of research and theorising. In. Schabracq, M.J., C. L Cooper and J.A.M. Winnubst (Eds.) Handbook of Work and Health Psychology. Chichester. John Wiley and Sons.

Schwam, K. 1998. The phenomenon of compassion fatigue in preoperative nursing. Journal of Advanced Nursing Studies 68:642-648.

Segall, A. and M. Burnett 1980. Patient education of physician role performance. Social Science Medicine 14a:269-278. 